University of Nebraska - Lincoln

DigitalCommons@University of Nebraska - Lincoln

Faculty Publications: Department of Teaching, Department of Teaching, Learning and Teacher Learning and Teacher Education

Education

$11-2006$

\title{
Informing Teacher Education through Cross-Cultural Teaching and Learning: Dialogic Inquiry into Japanese and Canadian School Experiences
}

Mitsuyo Sakamoto

Elaine Chan

Follow this and additional works at: https://digitalcommons.unl.edu/teachlearnfacpub

Part of the Curriculum and Instruction Commons, and the Teacher Education and Professional Development Commons

This Article is brought to you for free and open access by the Department of Teaching, Learning and Teacher Education at DigitalCommons@University of Nebraska - Lincoln. It has been accepted for inclusion in Faculty Publications: Department of Teaching, Learning and Teacher Education by an authorized administrator of DigitalCommons@University of Nebraska - Lincoln. 


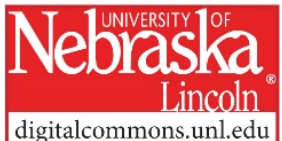

Published in Studying Teacher Education 2:2 (November 2006), pp. 213-228;

doi: 10.1080/17425960600983254

Copyright (C) 2006 Taylor \& Francis. Used by permission.

Published online January 24, 2007.

\title{
Informing Teacher Education through Cross-Cultural Teaching and Learning: Dialogic Inquiry into Japanese and Canadian School Experiences
}

\author{
Mitsuyo Sakamoto ${ }^{1}$ and Elaine Chan ${ }^{2}$
}

1. Department of English Language and Studies, Sophia University, Tokyo, Japan

2. Department of Teaching, Learning, and Teacher Education, University of Nebraska-Lincoln, USA

Corresponding author - Mitsuyo Sakamoto, Department of English Language and Studies, Sophia University, 7-1 Kioi-cho, Chiyoda-ku, Tokyo, 102-8554, Japan, email mitsuy-s@sophia.ac.jp

\begin{abstract}
This article examines the hermeneutic, narrative, and social co-construction of cultural understanding as two educators shared their teaching and learning experiences in Japanese and Canadian schools. Our dialogic inquiry reveals how perceptions of practices in one culture-including curricula in non-core, academic subjects, stances on student assessment, and attitudes toward extracurricular activities - were shaped by our prior school experiences. The study reveals that reconstruction of previous overseas experience and co-construction of meaning from this reconstruction can serve as a powerful means of enhancing understanding of cross-cultural issues. The reconstruction process also offers a means of engaging those who do not have international, educational experiences in discussion of these issues. The article concludes that seemingly casual, everyday conversations can offer insights that inform teacher practice as well as preservice teacher education.
\end{abstract}

\section{Sports Day Festival Story}

On a warm day in September, I sat on a makeshift stage next to two dusty old speakers and a podium that would later be used for the Sports Day ceremony. I was watching the Grade 3 children I had been working with since April practice 
their dance for Sports Day with the other Grade 3 class and the two Grade 4 classes. They were holding batons made of wooden dowels decorated with silver streamers and red, yellow, blue, or green strips of crepe paper, standing in lines according to the color of the streamers on their batons. The students had been practicing isolated parts of the dance for the past hour, but I had not yet seen the entire dance from beginning to end. As the music began, I noticed that the faces of the children were intent, and they were concentrating hard on their arm movements, their steps, and on placing their batons in the right position. They were dancing to an old Okinawan piece that is a combination of Chinese and Japanese influences to reflect the area of the country from which it originated. The music started off slowly and the students began dancing, first slowly to reflect the mood of the music, and then more quickly as they incorporated the baton movements and large group movements.

As I watched, I was struck by the beauty of the scene. On this warm but breezy day in early fall, the picturesque Hiei Mountain could be seen in the distance, and the view of the tiled roofs and gnarly trees from the private gardens of neighboring homes combined with the music and the solemn children dancing to create a picture that I can remember vividly even now. (Field note, September 1997)

This field note is a starting point for examining ways in which self-study of cross-cultural teaching and learning experiences, shared through a dialogic inquiry into Japanese and Canadian school experiences, may inform teacher education.

Elaine, one of the researchers in this study, wrote the field note following a day of observations at Wakakusu Elementary School (all names are pseudonyms, except those of the authors) in the northern suburbs of Kyoto, where she was a researcher for 2 years. Elaine spent 4 years in Japan in the 1990s as an English instructor and an educational researcher. She first went to Japan upon completion of a Bachelor of Education degree from a Canadian university and spent 2 years teaching English in Japanese junior and senior high schools. Without much knowledge or understanding of Japanese culture or schooling, some of the practices she observed while working with her Japanese teaching colleagues and students were puzzling - even frustrating - at times. These questions motivated a return to Japan, this time as an educational researcher in elementary schools, in an attempt to better understand the rationale and theories underlying practices common in the Japanese education system. The Sports Day Festival at Wakakusu Elementary School described above is one of many school events she observed during her time at the school.

Mitsuyo's schooling began in Japan and continued in Canada when her family moved there when she was 8 years old. She received a year and a half of full-time ESL instruction before being mainstreamed into a regular Canadian classroom. Thereafter, she went on to complete middle school, high school, and university in Canada, while at the same time maintaining and developing her written and oral Japanese skills. Even as a child with limited experience in Japanese elementary schools, she found some of the differences between her Japanese and Canadian classrooms extreme and could not help but compare them.We explore some of these responses in further detail in this paper. 
Elaine and Mitsuyo first met as teacher and student when Elaine audited the undergraduate Japanese course at a Canadian university where Mitsuyo was teaching. During that time, both were also doctoral students in the same department at the university, Mitsuyo in the second language education program and Elaine in the comparative education program. Given their common interests in language and identity issues, Japanese language and culture, and similarities in the graduate student context, it is not surprising their conversations often developed into discussions about cross-cultural issues in education. The realization that these insights were valuable and worth documenting inspired this study.

\section{Context of the Study}

Two of every five individuals in Canada are reported to be of ethnic background other than English, French, or Aboriginal (Canadian Heritage, 1996). Given the increasing diversity in Canadian society (Statistics Canada, 2001), enhancing awareness of diversity to avoid ethnocentrism and to provide an equitable learning environment for all children is essential. Teachers need to be aware of ways in which cultural diversity may influence classroom interactions, the implementation and interpretation of curriculum events, and the acquisition of academic skills.

Despite calls for antiracist and multicultural curricula, teachers may continue to overlook ways in which underlying cultural values influence classroom practices, and may even have difficulties detecting biases in their own teaching. Hamilton (1996) reported how classroom teachers, despite expressing a commitment to being culturally sensitive, conveyed conflicting messages throughout their practice. Cultural understanding is so embedded in our understanding of the contexts in which we live and work that it is often difficult to extricate and examine critically. Teachers may be unaware of the incompatibility between their standards and the expectations of their students (Corson, 2001). Misunderstanding between individuals of different cultural values and discourses has the potential to develop into intense conflict. Au \& Mason (1981) elaborated upon the relationship between cultural communication patterns in the classroom and academic achievement for students in Hawaii. More specifically, the academic performance of students improved dramatically when teaching accommodated communicative patterns more commonly used in the students' home cultures (Corson, 2001; Erickson, 1993; Hamilton, 1996; Jacob \& Jor-

dan, 1993b). This finding further reinforced the importance of teachers exploring ways of enhancing knowledge about different cultures in order to educate children of diverse cultural backgrounds more effectively and with greater sensitivity. In this way, drawing on overseas teaching and learning experiences may be a means of addressing the need for deeper understanding of ways in which cultural contexts may shape school practices. In addition, examining the overseas experiences of teachers as a source of professional development is also a means of addressing the tendency to overlook teacher knowledge of their practices (Yonemura, 1982).

As Canadian-educated teachers, we draw on our own experiences in Canadian schools as a point of reference and make the assumption that many of our readers are coming from a similar stance. We acknowledge and appreciate the many qualities of Canadian school 
systems, but in this paper we focus more specifically on what Canadian educators may learn from school systems in other countries, namely from Japanese schools.

\section{Traditional Comparative Educational Research vs. Hermeneutic Research of Cultural Understanding}

There has been much research comparing Japanese and North American education systems. Cummings (1980) examined ways the common curriculum and the text-based education system in Japan contributed to Japanese children having more equal access to education than American children. Peak (1991), White (1987), and Lewis (1995) examined ways in which goals of Japanese parents and teachers for preschool children differ significantly from those of North American teachers and parents. More specifically, they highlight ways in which Japanese educators discipline the children by encouraging them to manage one another and to initiate learning tasks in the classroom. In addition, White (1987) and Lewis (1995) also describe the many ways in which Japanese teachers place an emphasis on engaging their students in enjoyable and age-appropriate activities that are not necessarily academic in focus. These community-building activities are introduced especially in the beginning years of schooling but continue through their academic careers. Benjamin (1997) and Conduit and Conduit (1996) documented the experiences of foreign children and their parents in the Japanese elementary education system, and Tobin, $\mathrm{Wu}$, and Davidson (1989) compared preschools in Japan, China, and the United States to identify similarities and differences in the social and academic goals for children in each country respectively. While these studies highlight differences between Japanese and North American schooling, they do not address ways in which knowledge gained from one culture may transfer to teaching or learning in another culture. More specifically, they do not identify or trace ways in which cultural understanding of teachers' perceptions shape their teaching practices, nor do they document the hermeneutic process involved in meaning-making (Gadamer, 1975).

\section{The Purpose of This Study}

In the present study, rather than offering a comprehensive comparative account of Japanese and Canadian education systems, we document and examine the process of learning about ways in which differences in cultural background may be reflected in the interpretation of curricular practices. The aims of this study are three-fold. First, we examined our underlying cultural beliefs. Second, we engaged in the meaning-making process (Wells, 1994) through the sharing of stories of experience (Clandinin \& Connelly, 2000; Connelly

\& Clandinin, 1988) of teaching and learning in Canadian and Japanese elementary school settings. Third, we explored the implications that our findings hold for preservice teacher education and ongoing professional development of practitioners.

The importance of validating the personal practical knowledge of teachers (Connelly \& Clandinin, 1988) in teacher training has been documented elsewhere, and critical reflective inquiry should appropriately begin with one's own personal experience. This paper provides careful documentation of a collaborative meaning-making process as two teachers draw upon their own teaching and learning experiences as a resource for teaching. The 
two Canadian teachers, one of Japanese and one of Chinese descent, noted and analyzed their beliefs derived from teaching and learning experiences in Japanese and Canadian schools. Going into school systems very different from those that they experienced as children highlighted differences that enabled them to question their assumptions about appropriate curricula for their students. What is more important about this process is that the initial intention was not necessarily a conscious effort on the authors' part to participate in a reflective and critical research; what began as a casual conversation became a rich, informative meaning-making process, a study into one's belief with the aid of another. It is important to note how seemingly casual teacher talk may lead to insightful interaction about the practice of educators. As Cole and Knowles (2001, p. 46) stated,

The theories that we individually hold are not happenstance. They develop from the meanings we have derived from ordered and casual experience and the theories of others that we hear and see articulated around the kitchen table; in school classrooms and hallways; through various media including newspapers, television, films, and radio; in university lecture halls and seminar rooms; through academic and literary books, in our everyday work experiences; and so on.

We appreciate the ubiquitous nature of knowledge. In this study, we set out to explore and explicate the unconscious yet particular theories that we extricate from reflection upon our practices and document and share our discoveries afforded by our collegial dialogic inquiry.

Dewey's (1938) philosophy of the interconnectedness between experience and education helped us to acknowledge the strength of experience in shaping our interpretation of events lived years earlier as children in Japanese and Canadian schools respectively. Although these prior experiences occurred so long ago, through the eyes of children who did not have the information that we later gained as educators teaching and learning in Japanese and Canadian schools, these childhood experiences could also be viewed as a "frame of reference" (Polanyi, 1958) in that they became a point of reference for later experiences. Connelly \& Clandinin (1988) introduced the term" personal practical knowledge" (p. 25) as knowledge gained through a lifetime of experiences that teachers may draw upon to inform current teaching and learning situations. In this article, we present childhood stories of learning and adult stories of teaching, gained through experience in Japanese and Canadian schools, as personal practical knowledge that may inform subsequent teaching and learning.

We used a narrative inquiry approach (Clandinin \& Connelly, 2000; Connelly \& Clandinin, 1988) consisting of two parts. First, participants reflected upon and reconstructed their own teaching and learning experiences in Japanese and Canadian schools to explore their underlying assumptions of cross-cultural teaching. Second, this process developed into a heuristic co-construction of meaning-making, a collaborative self-study effort that documented and examined occurrences in which meanings were made and shared with one another (Vygotsky, 1981; Wertsch, 1985). We felt that this process of explicit expression and reflection upon specific crosscultural experiences with colleagues had the potential to enhance our understanding of our personal practical knowledge (Connelly \& Clandinin, 
1988). This, in turn, may inform the choices we make about pedagogy (Pratt, 1984). From this perspective, seemingly casual interactions, such as those that may occur among colleagues in a school staff room, may influence the interlocutors' ontology, and subsequently lead to the co-creation of knowledge unique to that context (Scribner, 1985). Wells (1994) noted how knowledge and expertise are shared achievements, arising from joint engagement in challenging activities that are personally significant to participants. Recognition of knowledge as shared is important, since "institutionally defined settings are often not readily recognized or accessible to conscious reflection by the individuals participating in them" (Wertsch, 1985, p. 215). Making explicit previously implicit assumptions held by teachers may contribute to understanding of the context from multiple perspectives. As Bruner (1990) wrote, "Meaning is rendered public and shared. Our culturally adapted way of life depends upon shared meanings and shared concepts and depends as well upon shared modes of discourse for negotiating differences in meaning and interpretation" (pp. 12-13; emphasis in original). We retraced the collaborative negotiation and meaning-making process as we explored the cultural beliefs and values underlying our teaching philosophies. Our aim was to document the process whereby knowledge and perceptions were created collaboratively (Vygotsky, 1981;Wertsch, 1985) through the sharing of narratives. We focused in particular on examining ways in which our knowledge and understanding changed as we moved from the perspective of an outsider who did not understand the rationale for practices seen in a particular setting, to that of an insider with an in-depth understanding of the rationale supporting the practices observed.

\section{Acknowledging, Sharing, and Co-Creating Knowledge}

We began with the notion that all individuals possess tacit personal knowledge (Polanyi, 1958) gained through previous experiences. The path we have taken thus far contributes to shaping our perspectives, which in turn influence the choices we make with regard to what we deem important. Simon (1992, p. 132) reminds us of "how much of our own histories and assumptions shape our ability to make sense of the world."

We realized that we both hold and adhere to educational beliefs that have been developed through participation in Canadian and Japanese school contexts. By analyzing and negotiating these values and beliefs explicitly, we were able to acknowledge them. Bruner (1990, p. 25) stated, "The best we can hope for is that we be aware of our own perspective and those of others when we make our claims of 'rightness' and 'wrongness' . . a turning away from 'authoritative meaning'."

Rather than approaching differences with the established notions about teaching, it may be more important to encourage teachers to explicate and share their assumptions with their colleagues. This may be one way of inducing the process of turning away from "authoritative meaning." In addition, discussion about practices used may refine teacher understanding and contribute to the spiral, evolutionary growth of knowledge (Schön, 1987). Leont'ev (1981) stated that "internal activity, which has arisen out of external, practical activity, is not separate from it and does not rise above it; rather, it retains its fundamental and two-way connection with it" (p. 58). This perspective aligns with Vygotsky's (1981) claim that cultural development first appears on an intermental plane, and is later internalized 
within the intramental plane. By conducting a narrative inquiry, the participant may organize his or her thoughts in a meaningful and holistic manner. This cognitive process leads to an internal transformation which is furthered by the sharing of narratives.

\section{Methodology}

The data for this studywere gathered through interviews and discussions of teaching and learning experiences in Canadian and Japanese elementary schools and also through observations and reflections following the viewing of video recordings of classroom and school community events in a Japanese elementary school. Initially, we planned to collect data from interviews and discussions alone. However, Elaine suggested that we incorporate media artifacts, in the form of videotapes she had recorded in Japan, to further our meaning-making process. School events and activities captured in the video acted as a catalyst for reinforcing previously discussed themes and for identifying themes that had been previously overlooked in interviews and discussions.

Interview questions were generated through an initial discussion addressing cross-cultural learning experiences and discrepancies between Japanese and Canadian education systems. Specifically, the questions addressed ways in which we, two Canadian educators who have resided in Japan for 8 and 4 years, respectively, interpreted our Japanese schooling experiences. We conducted interviews and conversations using a narrative approach (Clandinin \& Connelly, 2000; Connelly \& Clandinin, 1988, 1990; Jackson, 1987).

The sharing of narratives facilitated the process of exploring assumptions underlying practices we had observed in Japanese elementary schools. We focused in particular on stories of experience (Connelly \& Clandinin, 1988) as a means of examining ways in which previous experiences may contribute to personal and professional knowledge as teachers. A narrative approach enabled us to acknowledge the role of temporal and contextual factors that shaped the stories, and to address issues of relevance as they occurred in relation to other events in the context at the time. Like Bruner (1990, p. 77), we deemed narrative to be "one of the most ubiquitous and powerful discourse forms in human communication."

We had the advantage of knowing each other well before the study. We first met as teacher and student in a university course, and the relationship grew to one of friends and colleagues who have co-authored and co-presented papers at conferences. We often engaged in intellectual conversations pertaining to academic topics as well as personal and social matters. The many years we have known each other helped to nurture the relationship of sensitivity and respect (Cole \& Knowles, 2001) needed to make our dialogic inquiry an intellectual trek whereby trusting and collaborative rapport was possible from the onset of data collection. Furthermore, our relationship created a context whereby we held equal stakes in the research. In this way, the dialogic inquiry was a co-creative process in which power imbalances were not an issue. This contributed to the development of a "conversation-in-relation" (McIntyre \& Cole, 2001), with both of us engaged in a co-constructive pursuit to learn about a topic of mutual interest.

We conducted two interviews, one focusing on each participant, in January of 2000. The interviews lasted approximately 90 minutes per session and were audiorecorded, transcribed, and subsequently analyzed. Four follow-up discussions and written responses to 
issues raised in the initial interviews were done over the course of the following year. We first examined the interview transcripts individually to identify themes and discussed our interpretations in the follow-up sessions to triangulate our data. We then exchanged stories of experience with one another and wrote responses to the stories. Overall, the analysis of data took place on three different occasions, at three different levels. First, the interview transcripts were analyzed individually. Secondly, the data were analyzed together to examine and to discuss our individual analyses. Thirdly, themes that emerged from the data were reexamined as we responded to one another's stories of experience through comments and through reflections. From this process, new themes emerged, further contributing to our understanding of the role of cultural knowledge on pedagogical practices.

After the initial interviews, video-recorded examples of teaching and learning in a Japanese elementary school were examined. Elaine showed a 30-minute video clip recorded at Wakakusu Elementary School in Kyoto, Japan in September of 1997 when she was conducting long-term research on classroom and school practices in Japan. The video clip included details of students and teachers interacting in the context of regular activities, in addition to footage of the students preparing for their Sports Day performance. Following the first viewing of the video, the researchers discussed possible interpretations of the events, drawing on personal and professional experience in Japanese and Canadian school contexts to inform understanding of issues raised. Interpretations of the events seen in the video were supported by documents such as school notices to parents, photos taken at the event and prior to the event, student journals, and field notes following discussions and conversations with teachers, parents, and administrators. Themes that emerged through this viewing were recorded and addressed in further depth through subsequent discussions. This hermeneutic process enhanced our awareness of the power of collaboration in shaping our understanding of ways in which pedagogical practices may be influenced by cultural experiences.

\section{Research Findings: Moving across Cultures to Highlight the Power of Experience in Shaping Teaching}

Examination of the following excerpts, written in response to the audio-recorded followup discussions, raised pedagogical issues and demonstrated the process of the co-creation of knowledge. In the following excerpt, Mitsuyo spoke of her surprise upon entry into her first classroom in Canada in the mid-1970s.

\section{Mitsuyo's Experience in Her Canadian Classroom}

When I first walked into the room, I couldn't believe my eyes. I saw something I never thought I would find in a classroom - a doll house! It was fully furnished with little figurines, and we were free to play with it at any time, apart from when the teacher summoned us to sit around her to listen to stories. Most of the time, we had free time, and we were permitted to spend as much time as we wanted at the various stations that were set up around the room. Often, I shared the doll house with other girls or painted with other children, but the social 
interaction made the activities all the more enjoyable. The drawing station, with an ample supply of paints and newsprint paper, was another favorite of mine. Overall, the classroom atmosphere was casual and unstructured. Although I loved the freedom, I despised it a little as well, as I could not perceive any of this "play" as learning. A part of me felt like I was wasting valuable school time to play, since to me, learning consisted of studying from a textbook, doing penciland-paper tests, and listening attentively to what the teacher told us from the front of the classroom. It was as if the teacher did not have much to do, apart from supervising play in class.

Mitsuyo was surprised by the casual atmosphere in her Canadian school. She was shocked when she first came to Canada to see students slouching in their seats and sitting crosslegged on the floor. Things that she had been taught to pay careful attention to in her Japanese school, such as rigorous rote memorization of times tables or sitting up straight in your seat, did not seem to be emphasized as much in the Canadian system.

She was also appalled to learn how little attention noncore subjects seemed to receive in the Canadian education system. Art, physical education, and music did not seem to be given the same importance and rigor as English or math. These subjects seemed to lack structure and specific criteria or objectives that students were expected to master by a certain grade level. For example, in music, the children sang as a class but they did not learn how to play instruments or read music as part of the regular school curriculum, in comparison to children in Japan who are required to do so. In the physical education class, they played dodgeball or ran around the inside of the gym. None of this seemed to be formally assessed by the Canadian teacher.

Students in Japanese schools, on the other hand, follow a very structured curriculum in art, physical education, and music. In art, they sculpted with clay, made prints using wood blocks, used pastels, and experimented with different mediums, as Mitsuyo explains:

Mitsuyo: Art class is another class I thought was very different from our program over here (in Canada). I remember we were asked to use various mediums to create art. When I came over here, the art mediums we used were completely different from the mediums I used. In Japan, I used lots of clay, crayons, pastels, ... What else did I use ... crayon was a big one, and pencil crayons. Over here, like, tempera paint? ... and what do you call that paper?

Elaine: Oh, newsprint.

Mitsuyo: And, um, really poor quality crayons. I found them really waxy. The color doesn't really go on properly on paper, so I remember being a little frustrated.

The quality of art materials clearly had an influence on performance and motivation on Mitsuyo's part. Provision of proper materials gave a certain credence to the subject, envisioning it not as a peripheral subject but as part of the structured curriculum which encourages creativity on the part of learners. Mitsuyo continues: 
Mitsuyo: Uh, what else ... And we would go outside to sketch which we really don't do over here in Canada. Teachers don't take you outside and say, "Oh, let's draw the flowers" or whatever.

Excursions made outside of school reinforced and made explicit and meaningful the connection between the curriculum taught in class and the world outside.

Mitsuyo: In Physical Education, Japanese students were given specific tasks to perform, such as jumping over a set of stacking wooden boxes called "tobibako." First graders started with the lowest box, and the tasks became more difficult as the child progressed through elementary school. As for Music, students were expected to play the harmonica in the first grade in Japan, the recorder in the second grade, and an assortment of percussion instruments by the end of elementary school. The systematic learning in Japanese schools seemed to contribute to a sense of legitimacy in these subjects that seemed largely missing in the Canadian system.

Mitsuyo's surprise was rooted in the differences she perceived between her new classroom in Canada and the classrooms she had grown accustomed to in her Japanese schools. Although she likely had not intended to compare the two classrooms, her experience in Japanese schools was a point of reference for making sense of her experience after her arrival in Canada. Similarly, Elaine, in her reflection of her experience of visiting an elementary school in Japan during Sports Day preparations, interpreted the performance to be an example of the integration of music, physical education, team building, and art in the Japanese elementary school curriculum. The presentation was the culmination of months of preparation with students, teachers, parents, and administrators who had worked collaboratively through difficult and enjoyable stages with the goal of a perfect performance. Overall, she viewed Sports Day as an enjoyable school event. For Mitsuyo, who had spent her first years of formal education in a Japanese elementary school, the same image of a dance performance for Sports Day conjured memories of tension, hard work, and endless hours of tedious practice. Realization of this puzzling yet interesting difference in interpretation of the same Sports Day event was the beginning of numerous discussions.

When Elaine first saw and participated in Sports Day, the rationale behind much of the preparation and support for this event was foreign to her. She interpreted the extensive preparation that included long hours of practicing dances, line-up procedures, and seating patterns as the event drew closer to be a waste of valuable instruction time in academic topics such as math, language, science, and geography. Not only were teachers expected to prepare diligently for the event by practicing dance performances and sports events with their students, but they also forfeited class time in order to discuss preparations for Sports Day. They made decisions regarding the music, dance, and props. They also wrote letters home to parents to thank them for their support and to encourage them to attend Sports Day. The students' mothers were involved in guiding their children to decorate the batons and to make headbands for the performance. They were reminded to help their children to prepare their gym clothes for the daily practices. In the days prior to Sports 
Day, the school sent notices to homeowners in the neighborhood, requesting their support and patience as guests to the school would be parking in the streets in the surrounding area. Elaine did not initially understand the connection between the lengthy practices, the attention paid to detail, and the importance of working with peers and teachers toward a common goal. Nor did she realize that the organization and importance placed on Sports Day demonstrated the integration of subject areas across the curriculum. Through the experience of interaction with the students and teachers as they prepared for the event, she came to understand the rationale and its value.

As Elaine looked back on her participation as a long-term researcher at the school where the Sports Day event was taking place, she thought about how she had moved from being an outsider who did not understand the rationale for the school practices, to becoming closer to an insider through ongoing participation as an assistant teacher in the school community. She had developed a relatively comprehensive understanding of the rationale for school practices in this Japanese school and an informed understanding of the role of parents, teachers, students, administrators, and communities within the school system. She came to appreciate the dance performance as a mastery learning task, and the Sports Day event as a means of providing children with the opportunity to work together over an extended period of time in order to develop tolerance, patience, diligence, and a sense of team spirit. These were in addition to the physical benefits of practicing the sporting events, the emotional benefits of belonging to a group, and the sense of satisfaction following a successful performance. Time spent on practices no longer seemed like a waste of time. Elaine's understanding evolved to include an appreciation for practices unique to the Japanese education system.

\section{Analyzing Our Own Experiences as a Point of Reference}

We both used previous schooling experiences as a point of reference when faced with practices unfamiliar to us. We commented on the holistic curriculum of Japanese elementary schools, but we did so from different perspectives. Mitsuyo expressed her disappointment in the lack of rigor involved in learning art, music, and physical education-nonacademic subjects-in her Canadian elementary school. She compared it to her experiences of a highly regimented Japanese elementary school curriculum that progressed from basic skills to mastery. Elaine also addressed the benefits of a holistic curriculum with instruction in art, music, and physical education, but she did so by identifying ways in which the Japanese students had support for their nonacademic subjects that was far beyond what she had experienced as a student or a teacher in the Canadian system. Although neither researcher intended to compare the Canadian and the Japanese school systems, both began with their own experiences and used them as a reference point from which subsequent experiences were interpreted.

It is interesting to consider how this knowledge might be incorporated into the Canadian school system. We both acknowledged the benefits of implementing a project such as the Sports Day event described earlier. Elaine had gained an understanding about the Japanese elementary system that had the potential to inform her teaching and would readily support such an endeavor with her Canadian students. Upon return to Canada, however, 
she found herself in a system in which this new knowledge was not necessarily appreciated or welcomed. For example, when Elaine attempted to use Japanese management practices of focusing on student-directed rather than teacher-directed initiatives that were encouraged during the Sports Day preparations, she realized that the practices conflicted with those of her teaching colleagues educated in Canadian schools and faculties of education. The practice of allowing students to decide for themselves how they would organize an event, something so commonly done in Japan, was perceived as a shirking of responsibility by her Canadian teaching colleagues. In addition, her Canadian colleagues who had not had the opportunity to experience Sports Day personally did not seem to view this procedure as worthy of the effort, time, and energy needed to organize it. This incident led to the realization that in order for others to appreciate a different approach, it might be helpful or even necessary to experience it personally. The likelihood of large numbers of teachers experiencing education systems in foreign countries, however, is not high. This reality further emphasizes the importance of encouraging teachers to draw on and to discuss with teaching colleagues prior experiences in systems different from their own as a means of learning about diverse options for teaching particular skills to students in Canadian schools.

Mitsuyo was initiated into the Canadian education system as a Japanese child suddenly immersed in a new culture. Her impression of her Canadian classroom was from the perspective of a Japanese child, but her responses were examined from the perspective of an adult educator working in a Canadian education system. Her initial reaction to Canadian schools was that of surprise at the differences between her new school in Canada and the familiar Japanese school she had left behind.

Through discussion and reflection upon our interpretation of events described in the above passages, we were able to identify aspects of relevance in shaping our perceptions of specific events. Based on her previous experiences in her Japanese classroom, Mitsuyo's understanding of learning involved teacher-directed instruction, writing tests, and quiet individual work; Mitsuyo could not believe that she was permitted to "play" at school. She interpreted the freedom she encountered in her Canadian classroom as disorganized and undisciplined instruction.

Now trained as a teacher herself, Mitsuyo sees the value of experiential (Dewey, 1938), engaging, and motivated learning in facilitating the acquisition of knowledge. Examining her Japanese student experiences through her Canadian teacher perspective, she now realizes the possible discrepancies an Asian immigrant child may face upon entry into a Canadian classroom and feels compelled to ease the transition for the child. Her awareness enhances her ability to implement culturally sensitive practices. For example, she tries to incorporate various assessment tools to accommodate students who may be accustomed to being assessed using different means. She uses some pencil-and-paper tests as well as others that are more performance-based. She encourages collaborative learning. At the same time, she provides detailed rubrics, though not as detailed as those regularly used in Japanese schools, to ensure that students are aware of the criteria on which they are being evaluated.

These examples reinforced the strength of social narratives of teachers and students as a means of shaping their interpretation of curriculum activities. Methods and practices 
used with success in one country often do not have the same effect on students, or even teachers, when they are implemented in a society other than that in which they originated because the social narratives that shape the practices differ. Implementing different practices in classrooms may require an examination of the feasibility of changing the social systems in which the education systems were developed, and this is often not feasible or desirable. This realization reinforces the value of discussing cross-cultural teaching and learning experiences and testing possibilities of practices adopted from international experiences.

\section{Significance of the Study: Collaborative and Hermeneutic Development of Narratives}

Bruner (1990, p. 30) deemed "open-mindedness to be a willingness to construe knowledge and values from multiple perspectives without loss of commitment to one's own value." The process of examining and discussing explicitly the values and beliefs underlying our practices had an emancipating effect while at the same time engaging us in collaborative reflection which required the controlling of emergent thoughts (Bruner, 1986). The cocreation of knowledge through a collaborative analysis of stories may facilitate the examination of cross-cultural issues among teachers with international experiences. In this way, staff room talk has the potential to lead to meaningful, engaging, enlightening co-construction of knowledge - in this case knowledge pertaining to cultural artifacts and practices. Informal interactions among colleagues in a staff room may be rich in possibilities for collaborative inquiry.

Recent research examining preservice teacher training has highlighted the importance of validating student voice, promoting collegiality and collaboration among teacher candidates, and supporting collaboration among students in preservice teaching (Beck \& Kosnik, 2001; Russell, McPherson, \& Martin, 2001). We extrapolate from this idea to claim that collaborative dialog among in-service teachers is vital for the development of knowledge and represents a means of learning about diversity. The use of a narrative approach facilitated the process of engaging in an open-minded dialog. Stories addressing personal and professional experiences in Japanese and Canadian education systems in general and holistic curriculum in particular triggered new stories. The process gave rise to the creation of new perspectives (Jackson, 1987), and the "co-creation of meaning" (Wells, 1994, p. 9). By reliving otherwise dormant, unconscious experiences, the process contributed to our understanding of how past experiences inform our current teaching practices. In this way, the stories represent a means of accessing knowledge, a catalyst to retrieve information buried in our minds.

This process also highlighted the changing nature of experience. The stories shared did not remain the same; rather, they were constantly modified as understanding changed with subsequent responses by the interlocutor (Jackson, 1987). The process of interaction provided a means of reorganizing old beliefs to embrace new ones. This process was crucial to expanding our zone of proximal development (Vygotsky, 1981), to enhance our capacity to perform as educators sensitive to the cultural differences that students and teacher colleagues may bring to their teaching. Furthermore, the notion of collaborative meaning-making implies that professional development for individuals is also co-constructed. 
That is, the developmental path is determined by the meaning created in situ, which in turn influences the prospective epistemological creation.

\section{Conclusion}

This study highlights the potential of interaction and discussion among colleagues about cross-cultural teaching and learning experiences as professional development. The findings further support the far-reaching professional advantages, including reduced stress levels, higher moral and stronger commitment to teaching, as outlined by Le Maistre (2000) and Scott (1999). Casual conversation may be a source of insight in that it has the power to act as a catalyst to further support collaborative inquiry and the exchange of information. This kind of discussion can validate the voices of teachers and may contribute to the development of more thoughtful and culturally sensitive teaching practices.

Engaging in this hermeneutic process of examining and reflecting upon our own experiences enhanced our sense of cultural sensitivity to inform our current work as teachers. The experience of interacting with foreign cultures shaped perceptions of our childhood experiences as well as our view of our work as teachers. The process represents a means for educators to take initiative in dialogic inquiry (Wells, 1999) and engage in communal enculturation by becoming active agents in knowledge creation. In this way, our study may provide educators with clues to dealing with differences in perspective that may be associated with cultural differences. These changes may in turn shape how we teach and interact with our students and how we work with our colleagues. Heightening educators' awareness of the importance of cultural sensitivity and understanding (Jacob \& Jordan, 1993a) may be a means of meeting the needs of an increasingly diverse student population in Canada. Thus it seems vital for teacher educators to provide guidance for preservice candidates and practitioners, to encourage autonomy in recognizing and capturing overseas experiences as teaching and learning moments.

\section{References}

Au, K. H., \& Mason, J. (1981). Social organizational factors in learning to read: The balance of rights hypothesis. Reading Research Quarterly, 17, 115-152.

Beck, C., \& Kosnik, C. (2001). From cohort to community in a pre-service teacher education program. Teaching and Teacher Education, 17, 925-948.

Benjamin, G. R. (1997). Japanese lessons: A year in a Japanese school through the eyes of an American anthropologist and her children. New York: New York University Press.

Bruner, J. (1986). Actual minds, possible worlds. Cambridge, MA: Harvard University Press.

Bruner, J. (1990). Acts of meaning. Cambridge, MA: Harvard University Press.

Canadian Heritage. (1996). Multicultural Canada: A demographic overview. Statistics on multiculturalism in Canada. Retrieved April 11, 2006, from http://www.canadianheritage.gc.ca/progs/multi/ pubs/multi-stats_e.cfm

Clandinin, D. J., \& Connelly, F. M. (2000). Narrative inquiry: Experience and story in qualitative research. San Francisco: Jossey-Bass. 
Cole, A. L., \& Knowles, J. G. (2001). Lives in context: The art of life history research. Walnut Creek, CA: Alta Mira Press.

Conduit, A., \& Conduit, A. (1996). Educating Andy: The experiences of a foreign family in the Japanese elementary school system. Tokyo, Japan: Kodansha.

Connelly, F. M., \& Clandinin, D. J. (1988). Teachers as curriculum planners: Narratives of experience. Toronto, Canada: OISE Press.

Connelly, F. M., \& Clandinin, D. J. (1990). Stories of experience and narrative inquiry. Educational Researcher, 19(5), 2-14.

Corson, D. (2001). Language diversity and education. Mahwah, NJ: Erlbaum.

Cummings, W. K. (1980). Education and equality in Japan. Princeton, NJ: Princeton University Press.

Dewey, J. (1938). Experience and education. New York: Touchstone.

Erickson, F. (1993). Transformation and school success: The politics and culture of educational achievement. In E. Jacob, \& C. Jordan (Eds.), Minority education: Anthropological perspectives (pp. 27-51). Norwood, NJ: Ablex.

Gadamer, H-G. (1975). Truth and method. New York: Seabury Press.

Hamilton, M. L. (1996). Tacit message: Teachers' cultural models of the classroom. In F. A. Rios (Ed.), Teacher thinking in cultural contexts. Albany, NY: State University of New York Press.

Jackson, P. W. (1987). On the place of narration in teaching. In D. C. Berliner, \& B. V. Rosenshine (Eds.), Talks to teachers: A festschrift for N. L. Gage (pp. 307-328). New York: Random House.

Jacob, E., \& Jordan, C. (1993a). Understanding minority education: Framing the issues. In E. Jacob, \& C. Jordan (Eds.), Minority education: Anthropological perspectives (pp. 3-11). Norwood, NJ: Ablex.

Jacob, E., \& Jordan, C. (1993b). Understanding educational anthropology: Concepts and methods. In E. Jacob, \& C. Jordan (Eds.), Minority education: Anthropological perspectives (pp. 15-24). Norwood, NJ: Ablex.

Le Maistre, C. (2000). Mentoring neophyte teachers: Lessons learned from experience. McGill Journal of Education, 35, 83-87.

Leont'ev, A. N. (1981). The problem of activity in psychology. In J. V.Wertsch (Ed.), The concept of activity in Soviet psychology (pp. 37-71). Armonk, NY: Sharpe.

Lewis, C. C. (1995). Educating hearts and minds: Reflections on Japanese preschool and elementary education. Cambridge, England: Cambridge University Press.

McIntyre, M., \& Cole, A. L. (2001). Conversations in relation: The research relationship in/as artful self-study. Reflective Practice, 2, 5-25.

Peak, L. (1991). Learning to go to school in Japan: The transition from home to preschool life. Berkeley, CA: University of California Press.

Polanyi, M. (1958). Personal knowledge. Chicago: University of Chicago Press.

Pratt, D. (1994). Curriculum planning: A handbook for professionals. Toronto, Canada: Harcourt Brace.

Russell, T., McPherson, S., \& Martin, A. K. (2001). Coherence and collaboration in teacher education reform. Canadian Journal of Education, 26, 37-55.

Schön, D. (1987). Educating the reflective practitioner. San Francisco: Jossey-Bass.

Scott, N. (1999). Teacher induction in New Brunswick. Journal of Professional Studies, 6(2), 15-22.

Scribner, S. (1985). Vygotsky's uses of history. In J. Wertsch (Ed.), Culture, communication and cognition (pp. 119-145). Cambridge, England: Cambridge University Press.

Simon, R. I. (1992). Teaching against the grain: Texts for a pedagogy of possibility. Toronto, Canada: OISE Press. 
Statistics Canada. (2001). Immigrant population by place of birth, by census metropolitan areas. 2001 Census. Retrieved August 24, 2006, from http://www12.statcan.ca/english/census01/products/ highlight/Immigration.

Tobin, J. J.,Wu, D. Y. H., \& Davidson, D. H. (1989). Preschool in three cultures: Japan, China, and the United States. New Haven, CT: Yale University Press.

Vygotsky, L. S. (1981). The genesis of higher mental functions. In J. V.Wertsch (Ed.), The concept of activity in Soviet psychology (pp. 144-188). Armonk, NY: Sharpe.

Wells, G. (1994). Introduction. In G. Wells (Ed.), Changing schools from within: Creating communities of inquiry (pp. 1-35). Toronto, Canada: OISE Press.

Wells, G. (1999). Dialogic inquiry. Oxford, England: Oxford University Press.

Wertsch, J. V. (1985). Vygotsky and the social formation of mind. Cambridge, MA: Harvard University Press.

White, M. (1987). The Japanese educational challenge: A commitment to children. New York: The Free Press.

Yonemura, M. V. (1982). Teacher conversations: A potential source of their own professional growth. Curriculum Inquiry, 12, 239-256. 